\title{
Child spacing and contraception among the poor in Zambia
}

This article was published in the following Dove Press journal:

Open Access Journal of Contraception

26 March 2010

Number of times this article has been viewed

\author{
Vijayan K Pillai' \\ Rashmi Gupta ${ }^{2}$ \\ 'School of Social Work, University \\ of Texas at Arlington, Arlington, TX, \\ USA; 'Department of Social Work, \\ San Francisco State University, San \\ Francisco, CA, USA
}

Correspondence: Vijayan K Pillai School of Social Work, 2II South Cooper Street, University of Texas at Arlington, Arlington, TX 76019, USA

Tel +l 8172725353

Email drpillai@yahoo.com

\begin{abstract}
For decades, family planning programs have targeted women in developing countries. These programs bestow a great deal of autonomy on women with respect to fertility decision making. It is well known that a number of close relatives in multigenerational and extended family systems influence women's fertility decisions with respect to child spacing and contraceptive use. One approach toward a systematic study of fertility decision making is to explicitly consider the husband's influences on fertility decision making. This study examines the effects of a selected number of factors on the desired birth interval lengths. We interviewed husbands and wives separately from 165 randomly selected households from two poor neighborhoods in the city of Kitwe, Zambia. Three ordinal birth interval groups were obtained for both husbands and wives separately. The effect of selected factors on the likelihood of influencing the three groups was examined using ordinal logistic regression methods. Data from husbands and wives were analyzed separately. Qualitative methods such as semistructured interviews were used to gather extensive information on the various factors that husbands and wives perceive to influence their child spacing decisions. We found differences in accounts with respect to child spacing between husbands and wives, likely due to a lack of communication. A gender-sensitive approach is necessary to promote spacing methods among poor couples in Zambia.
\end{abstract}

Keywords: child spacing, contraceptive use, correspondence analysis, couple decision making

\section{Background}

Family planning education has been vital to increasing the number of modern family planning acceptors in developing countries. Family planning programs urge individuals to not only seek family planning advice but also encourage couples to discuss and select suitable contraceptive methods. A number of studies have examined the process of fertility and contraceptive decision making to reduce family size. ${ }^{1}$ Since family formation usually progresses through a number of stages such as starting, spacing and finally stopping fertility, it is necessary to understand the processes of decision making at each of these three stages. ${ }^{2}$ Among the three stages, child spacing decision making spans a large proportion of the reproductive life of the couple. However, very few studies have investigated the various aspects of joint decision making with respect to spacing or birth intervals. The objective of this study is to investigate the effect of a few selected factors on preferred duration for child spacing or birth interval among low income households in Zambia.

At a theoretical level, fertility is seen as an outcome of several social and structural influences. The most important of these structures in developing countries include a patriarchal system which encourages high fertility. ${ }^{3}$ Women are seen as passive partners submit your manuscript | www.dovepress.com

Dovepress
Open Access Journal of Contraception 2010:1 I-8 I

(C) 2010 Pillai and Gupta, publisher and licensee Dove Medical Press Ltd. This is an Open Access article which permits unrestricted noncommercial use, provided the original work is properly cited. 
who cooperate with husbands and older male members of the family in meeting their demands for a large number of children. ${ }^{4,5}$ As a result, social structural theories seldom recognize the ongoing nature of fertility decision making. Social structural theories assert that decisions are made by the patriarch and simply imposed on women. In stark contrast with the theoretical stance of structural theories, a few have argued that no explicit decisions are made with respect to family size. Couples are seen as drifting into a family size with a number of unplanned births. For example, in South India couples seldom make conscious decisions with respect to achieving the next parity. ${ }^{6}$ Kritz and colleagues suggest that the norm of joint reproductive decision-making is becoming widespread in sub-Saharan Africa. ${ }^{7}$ Others argue that in Africa, spouses live separately and their worlds are separate emotionally, economically, and socially. Owing to this separateness, there is seldom any communication with respect to achieving the next parity. ${ }^{8}$

Even when each spouse makes individual decisions to have or not to have the next child, it may not result in an agreement between the spouses. In order for one spouse to agree not to have the next child both spouses must individually decide not to have the next child. This type of communication usually occurs when fertility becomes a conscious choice. ${ }^{9}$ Often each spouse reaches these agreements based on the perception of demand for children of the other spouse. ${ }^{10}$ Studies which have focused on reproductive decision making attempt to examine the social structural factors associated with agreement or disagreement with respect to the next parity. ${ }^{11,12}$ These studies have yielded dissimilar results. Characteristics of wife and husband are considered as factors that influence the likelihood of agreement. Dodoo found no significant relationship between relative status of spouses and likelihood of agreement. ${ }^{11}$ Ezeh found that a woman's contraceptive attitude depends not only on her individual characteristics but also on those of her husband. ${ }^{12}$

In general, research on reproductive decision making appears to suffer from a number of drawbacks. First, social structural theories pay little attention to the decision making process that characterizes family formation. It is assumed that the decision to either delay or not to delay the next child is not of any significant theoretical importance in traditional societies, where fertility is not a result of conscious choice. This assumption is questionable. Each spouse may make his or her own reproductive decisions even though other family members may influence these decisions. When spouses make decisions, husbands' decisions are likely more important than wives'. ${ }^{13}$ As a result, it is assumed that the decisions with respect to birth spacing and length of the birth intervals are mainly influenced by the husband. As societies become more modern, spouses begin to discuss their preference for the next child as well as the timing of the birth. These discussions result in agreements as well as disagreements between the couple. ${ }^{14}$ When there is either agreement or disagreement it is assumed that the factors that lead to disagreement are the same. Understandably, gender influences on couple decision making shape the preferences for length of birth intervals among husbands and wives.

\section{Material and methods}

The social influence theory suggests that preferences with respect to the length of the birth interval may be influenced by advice people receive from significant others. Social groups that are seen to provide legitimate information also may influence the length of the interval. ${ }^{15}$ Thus there is a difference between people who receive advice and those who do not with respect to the length of the interval. Those who receive advice are more likely to prefer longer birth intervals than those who do not. The social influence theory also asserts that a perceived increase in the legitimacy of the adviser is likely to increase its effectiveness. ${ }^{16}$ In addition, when individuals in primary relationships enter into discussion with respect to length of birth interval as well as spacing methods, they are more likely to make rational choices with respect to the length of the birth interval. ${ }^{17}$

\section{Sample}

Two urban neighborhoods from the city of Kitwe in the Zambian Copperbelt region were randomly chosen. The maps for these neighborhoods were obtained from the Kitwe town planning office. The maps provided general information on the location of each household in the neighborhood. These maps were updated by locating new households. Several onsite visits to the neighborhoods were made to revise the map in order to record the number, type, and location of the households. One hundred sixty five households were randomly selected at the research site. In order to gather data on reproductive decision making, a questionnaire was developed. This questionnaire was revised after it was pretested on 20 couples from randomly selected households from a neighborhood in Ndola which is located near Kitwe. All households in which either the husband or wife had completed questionnaires are included in this study. Questionnaires were administered separately to the husband and wife. Husbands and wives were interviewed simultaneously in order to limit opportunities for spouses to influence each 
other's feelings and opinions on items in the questionnaire. Female interviewers were used to interview the wives. All interviewers were fluent in Nyanja, Bemba, and English.

The variables in this study relate to four domains of reproductive decisions making: discussion of preferred interval length with partner, discussion about a method to achieve preferred interval, receiving advice about desirable birth interval, and the type of fertility control method ever used. The variable 'Bestinth' and 'bestint' measure the preferred length of birth interval reported by husband and wife respectively. They were asked, 'What do you think is the best length of time to have between pregnancies'. The responses were recorded in months. The birth intervals in months were categorized as follows. Category 1 is composed of preferred interval of 12 months or less; category 2 included all intervals greater than 12 months and less than 24 months; category 3 is made up of all respondents who preferred intervals between 24 months and less than 35 months; category 4 included all the intervals between 36 and 48 months and the last category is composed of intervals greater than 48 months.

The variable 'Hwintcs' is a dichotomous variable associated with the question asked of all wives, "Have you and your husband ever discussed the best length of time to have between pregnancies". Those who responded 'yes' are coded 1 and the rest 0 . The corresponding dummy variable for husbands is 'hwintcsh'.

The variable 'advmeth' is a dichotomous variable related to the question asked to all wives, "Have you ever talked or received advice from anyone on methods, how to space your children or prevent pregnancy". Those who responded 'yes' are coded 1 and the rest 0 . The corresponding dummy variable for husbands is 'advmethh'.

The variable, 'hwintmd' and 'hwintmdh' represent responses by wife and husband respectively to the question, "Have you and your husband or wife ever talked about different methods or ways to space your children". The two variables are categorical, coded 1 for yes and 0 for the rest.

The variable 'methused' is a categorical variable related to the question asked of all wives, 'Can you tell me what methods you and your husband have ever used to space your children'. The responses varied widely. All the responses were re-categorized into three groups. The first group, coded 1, comprises all those who used 'traditional methods' only for spacing children. Category 2 is composed of all those who reported that they used both modern and traditional methods. The last is a category of all who used modern methods only. The corresponding variable for husbands is 'methusedh'.

\section{Results}

Figure 1 presents the most frequently preferred birth interval category among husbands and Figure 2 presents the same for wives. The model category of preferred length of birth interval is one to two years for both husbands and wives.

Table 1 presents the distribution of responses to four selected concepts related to preferred length of intervals. The percentage of wives who said that they discussed the best length of time (see variable Hwintcs) for spacing birth is about 11 percentage points less than the percentage for husbands. However about $17 \%$ more wives than husbands received advice (see variable Advmeth) on how to space children. Even though about $82 \%$ of wives received advice about how to space their children, a far fewer percentage of wives said that they discussed spacing methods (see Hwintmd) with their husbands. About $32 \%$ of the husbands said that they have discussed spacing methods with their wives, while only half that percentage of wives, less than $16 \%$, said that they discussed spacing methods with their husbands. Thus there is a noticeable gap between wives and husbands with respect to their statements on discussion of methods for spacing. Roughly the same proportion of husbands and wives (see variable Methused) 23\% and $25 \%$, respectively said that they had used (ever used) modern methods of birth control. Even though about $82 \%$ of the wives received advice with respect to methods of child spacing, only $25 \%$ of all wives said that they had used modern methods. Roughly the same percentage of husbands also said that they had used modern methods. It appears that wives were as likely as husbands to have used modern methods in spite of the fact that a much higher percentage of wives than husbands received advice about child methods.

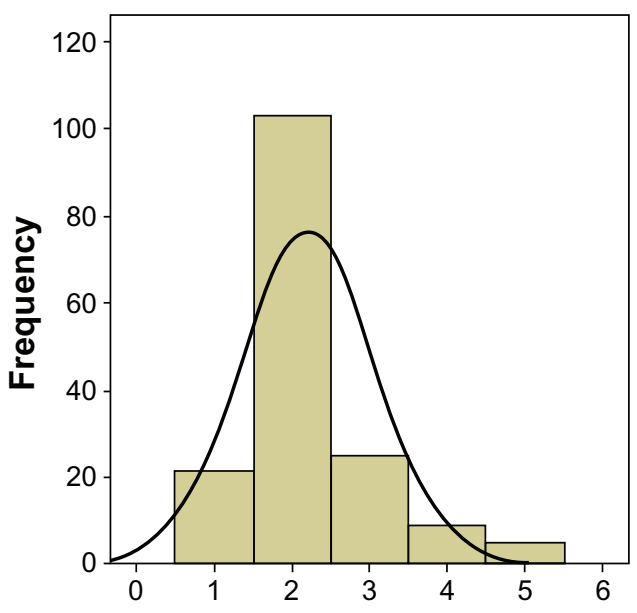

Figure I Frequency distribution of preferred birth intervals among husbands. Notes: I, less than one year; 2, I to 2 years; 3, 2-3 years; 4, 3-4 years; 5, 4 years or more. 


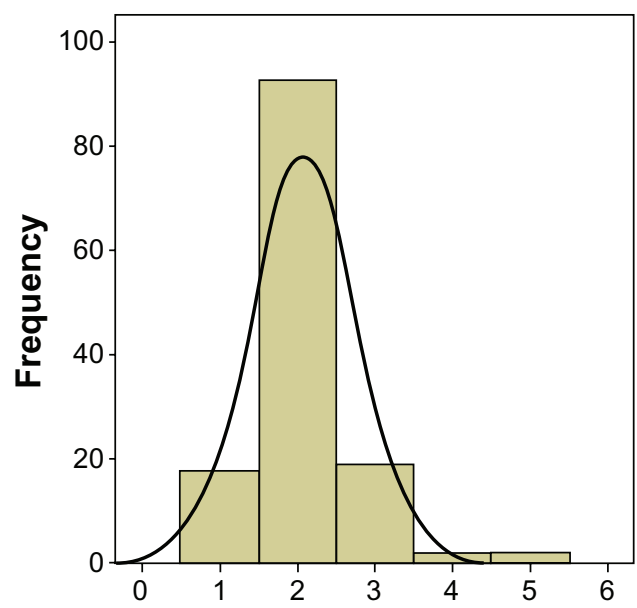

Figure 2 Frequency distribution of preferred birth intervals among wives. Notes: I, less than one year; 2, I to 2 years; 3, 2-3 years; 4 , 3-4 years; 5,4 years or more.

In general, traditional methods of contraception are far more widely used to space children than either modern methods or a mix of both traditional and modern methods. Among husbands who preferred a short birth interval, less than one year, about $70 \%$ used only traditional methods. Compared with these husbands, a slightly higher proportion of the husbands who preferred an interval of one to two years, the model category of birth interval preference, used traditional methods of contraception. About $70 \%$ of the husbands who preferred birth intervals of three to four years claimed to have used traditional contraceptives. Use of modern methods of contraception for child spacing among husbands was limited to those who preferred birth intervals two to three years or higher.

Traditional methods of contraception were far more widely preferred among wives to space children than either modern methods or a mix of both traditional and

Table I Percentage distribution of husband and wives for selected determinants of preferred birth intervals

\begin{tabular}{lll}
\hline Variable & Husband (yes) & Wives (yes) \\
\hline Advmeth & $65.2 \%$ & $82.4 \%$ \\
Hwintcs & $51.9 \%$ & $40.5 \%$ \\
Hwintmd & $32.6 \%$ & $15.5 \%$ \\
Methused & & \\
$\quad$ Traditional & $67.1 \%$ & $58.6 \%$ \\
Mix & $9.7 \%$ & $16.0 \%$ \\
Modern & $23.2 \%$ & $25.3 \%$ \\
Bestint & & \\
$<1$ year & $20.3 \%$ & $21.8 \%$ \\
I-24 years & $61.7 \%$ & $63.9 \%$ \\
$>24$ years & $18.0 \%$ & $14.3 \%$ \\
\hline
\end{tabular}

modern methods. Among wives who preferred a birth interval of one to two years, the model category, about $57 \%$ used only traditional methods. A slightly higher percentage (64\%) of wives who preferred an interval of about two to three years used traditional methods of contraception. The use of modern methods of contraception for child spacing among wives was higher among those who preferred birth intervals one to two years than among the other categories of preferred birth intervals. In the model category of preferred birth interval, one to two years, about $72 \%$ of the husbands and $57 \%$ of the wives stated that they had used traditional birth control methods.

We used ordinal logistic regression to explore the effect of selected determinants on the length of preferred birth intervals. The analysis was done separately for wives and husbands. Though data were collected from 165 households, the information on the dependent variables was available for fewer households. The sample sizes for the two groups are 133 for wives and 147 for husbands, respectively. The independent variables are 'hwintcs', 'advmeth', and 'hwintmd', and the dependent variables is 'bestint' (for wife). The independent variables are 'hwintcsh', 'advmethh', and 'hwintmdh', and the dependent variables is 'bestinth' (for husband). The birth intervals in months were categorized as follows. Category 1 is composed of a preferred interval of 12 months or less; category 2 included all intervals greater than 12 months and less than 24 months; category 3 is made up of all respondents who preferred intervals greater than 36 months.

In ordinal logistic regression, the dependent variable is conceptualized as latent dimension $y^{*}$ manifested as an ordinal variable. The dependent variable, the latent dimension, is an expected outcome of the effects of a number of selected variables based on a specified theory. The relationship between the outcome and the independent variables $(x)$ is expressed as a linear function, $y_{i}^{*}=\beta \chi_{1}+. .+\varepsilon \cdot y_{i}=m$ if $\alpha_{m-1} \leq$ $y_{i}^{*} \leq \alpha_{m}, m=1,2, \ldots m$ and where the $\alpha \mathrm{s}$ are boundaries of the dependent variable. This model is based on the proportional odds assumption that the effect of the independent variables on the outcome logistic are the same. This assumption is easily tested using a score test. If the assumption is not satisfied it is appropriate to shift to a method of analysis which assumes non-proportional odds. ${ }^{18}$

Table 2 presents the results of ordinal logistic regression for husbands based on the proportional odds model. Table 3 repeats the analysis for wives. The tables present both the gross effects for each of the four variables as well as net effects. The variables 'methh1' and 'methh2' are dummy 
Table 2 Gross and net effects of selected determinants of preferred length of birth interval (Husband)

\begin{tabular}{lllll}
\hline Variable & $\begin{array}{l}\text { Estimates } \\
\text { (Gross) }\end{array}$ & Odds ratio & $\begin{array}{l}\text { Estimates } \\
\text { (Ref) }\end{array}$ & Odds ratio \\
\hline Hwintcsh & 0.134 & 1.140 & 0.391 & 1.350 \\
Aovmethh & 0.100 & 1.100 & 0.049 & 1.070 \\
Hwintmdh & $-0.44 \mathrm{I}$ & 0.640 & -0.398 & 0.570 \\
MethhI & -1.21 I* $^{*}$ & 0.280 & $-0.227^{*}$ & 0.290 \\
Methh2 & -0.895 & 0.410 & -0.834 & 0.430 \\
\hline
\end{tabular}

variables for groups using traditional methods, and a mix of modern and traditional methods respectively. The reference group is the left out category, those who have used modern methods. Husbands who used traditional methods are more likely to belong to shorter preferred birth intervals than longer. The selected determinants, except 'methh1' have no significant effect on the preferred length of birth interval for husbands. However, among wives, the variable Advmeth (received advice on child spacing methods) had a significant effect on likelihood of preference for birth interval of one to two years. The odds of belonging to the group of wives who prefer long intervals increase for those who have received advice with respect to child spacing. The odds are about 2.8 times the odds among those who have not received any advice. There is a significant difference between husbands and wives with respect to the factors that influence the preferences for length of birth intervals.

Table 4 presents the results of the test of the proportional odds assumption. We test the null hypothesis which states that the location parameters (slope coefficients) are the same across response categories. The chi-squared values for both husband and wife are not significant at the 0.05 level satisfying the proportional odds assumption.

Since prior use of birth control method has a significant effect on the preferred length of birth interval among husbands, we explored the association between the two factors. In order to further assess the relationship between birth control methods

Table 3 Gross and net effects of selected determinants of preferred length of birth interval (Wife)

\begin{tabular}{lllll}
\hline Variable & $\begin{array}{l}\text { Estimates } \\
\text { (Gross) }\end{array}$ & Odds ratio & $\begin{array}{l}\text { Estimates } \\
\text { (Ref) }\end{array}$ & Odds ratio \\
\hline Hwintcs & -0.739 & 0.52 & $-0.65 \mathrm{I}$ & 0.52 \\
Aovmeth & $\mathrm{I} .115$ & $3.05^{*}$ & 1.028 & 2.79 \\
Hwintmd & -0.345 & 0.74 & -0.287 & $1.19 \mathrm{I}$ \\
Methwl & -0.379 & 0.68 & -0.088 & 0.920 \\
Methw2 & -0.823 & 0.44 & -0.764 & 0.470 \\
\hline
\end{tabular}

Table 4 Test of parallel lines for proportional odds assumption

\begin{tabular}{llll}
\hline Wife & & & \\
Model & -2 Log Likelihood & Chi-square & df \\
Null hypothesis & 77.152 & & \\
$\begin{array}{l}\text { General } \\
\text { Husband }\end{array}$ & $73.019,4.133$ & $4.133(\mathrm{~ns})$ & 5 \\
Model & -2 Log Likelihood & Chi-square & df \\
Null hypothesis & 55.713 & & \\
General & $52.906,2.807$ & $0.422(\mathrm{~ns})$ & 5 \\
\hline
\end{tabular}

Abbreviation: ns, not significant.

and the preference for length of birth intervals, we examined the association using correspondence analysis. Correspondence analysis is a method to describe the pattern of association that may exist between column and row categories in cross tables. It is very similar to factor analysis in terms of its purpose for which it is used in the social sciences. Distance metrics are used to measure the relationship between column and row categories and factors are extracted that account for the relationship between column and row categories. In exploring the relationship between birth interval preference and contraceptive method used, the correspondence analysis method expresses the distances to the origin from each of the row and column cells as 'inertia'. The total inertia (obtained using row principal normalization method) is explained by two dimensions as presented in Table 5. About $57 \%$ of the inertia $(0.051 / 0.089)$ is explained by the first dimension. The square root of the inertia is expressed as a singular value of 0.225 and it presents the amount of correlation between row and column scores. The correlation between method-use and preferred length of birth interval among husbands appears to be weak.

We had followed up on all structured questions on child spacing in the Kitwe survey with semi-structured questions. The qualitative responses to the questions are analyzed using content analysis. The semi-structured interviews focused on obtaining data on the decision making processes as well as spacing methods used by couples. The interview began by asking what they thought was a reasonable space between births. Given that both husband and wife may prefer dissimilar birth intervals, we asked if they discussed their birth interval preferences with each other. In addition, information on all the sources as well as content of advice on the choice of birth intervals also was collected. If the information gathered by couples led to a discussion about selection of a spacing method, the content of such discussion as described by husband and wife separately was gathered. Finally, we asked what methods they had used if they ever spaced their children. 
Table 5 Summary for husbands

\begin{tabular}{lllllll}
\hline Dimension & Singular value & Inertia & Chi-square & Sign & & \multicolumn{2}{l}{ Proportion of inertia } \\
\cline { 5 - 7 } & & & & Accounted for & Cumulative \\
\hline $\mathrm{I}$ & 0.225 & 0.051 & & 0.568 & 0.568 \\
Total & 0.196 & 0.039 & & 0.432 & 1.000 \\
\hline
\end{tabular}

Note: ${ }^{a}$ Eight degrees of freedom.

The median ages of the husbands and wives are 44 and 30 years, respectively. Ages as stated by husbands were concurred by $48 \%$ of wives and ages stated by wives were concurred by about $50 \%$ of husbands. The average length of the birth interval preferred by husbands is 26 months while the wives reported a slightly lower average, 24 months. The most important reason for spacing among mothers was to ensure good health for their last child. The term 'grow' was mentioned about 64 times during the qualitative interview. A second reason, though far less important than the concern of the health of the last child was the mother's health. One respondent said "Nurses from the family planning clinic told me that the best length of time is two years so that I can breast-feed my children during that time".

Husbands were, in general, more concerned about the health of the child than with the health of the mother. Several terms such as 'growth', 'health', and 'breast feeding' were used well over 100 times during the qualitative interview with the husbands. Terms such as 'power', 'rest', and 'strength' referring to the health of the mother were mentioned well below 100 times. Respondents who showed concern for the health of the mother through supporting large birth intervals were also more likely to suggest that large birth intervals benefit the health of the child also. One respondent said, "I have talked to my uncle this year. I asked my uncle to say is it necessary to have the next child when the other one has one year. He answered to say no - it is not advisable because if children are narrowly spaced they can suffer from malnutrition so the best length should be two years".

About $36 \%$ of the wives and $42 \%$ of the husbands said that they discussed birth spacing. Most of the discussion between couples was centered on the health of the child and mother. The term 'grow' was mentioned 24 times. One respondent said "yes, when I had a first-born child, I told my wife that my parents had told me to wait two years for the baby to grow well. This applied to the second wife as well". Far fewer references were made with regard to mother's health.

Wives stated that discussing birth spacing with their husbands yielded agreement most of the time. Wives also mentioned that 'growth and wellbeing' of children was a central concern in making spacing decisions. One respondent said, "I discussed with husband and he said three years is the best length of time for the baby to grow and prevent the child from suffering alone". Wives felt that their health as mothers was not stressed in the discussion.

While about $28 \%$ of the husbands reported that they received some form of advice about spacing methods, only about half, $16 \%$ of the wives said that they received advice about spacing methods. Husbands in general suggested the use of medicine for achieving the desired birth interval. The term 'medicine' was mentioned about 18 times. However, seven of these instances referred to the use of African medicine. Other methods husbands preferred were 'stopping intercourse' and 'breast feeding'. One respondent said, "My grandmother told me to use African medicine because when my wife uses it she cannot become pregnant and the child cannot be affected even if I sleep with my wife".

Very few wives mentioned discussing traditional methods with their spouse. Most said that discussion focused on modern methods. Use of modern methods, visiting family planning clinics, and contacts with nurses and doctors were discussed. One respondent said, "the doctors from the family planning clinic advised on different methods. One doctor say she can use pills and a diaphragm if she want to space her children. They told me to take the pill before mating with my husband".

Nearly $90 \%$ of the husbands preferred to seek advice from medical facilities while the rest mentioned the 'elders' as a source of information. While about $90 \%$ of the wives mentioned 'medical facilities' as a preferred source of information, the rest mentioned that they would like to learn about the use of 'inanga' (an object tied around the waist to prevent pregnancy) from elder women.

Most husbands said that their discussion of spacing methods concerned those available through family planning clinics, hospitals, and doctors. A few of them said that they also discussed the use of traditional methods such as abstinence. One husband said, "Elder people told me when I was about to get married. They told me that it is not advisable for a man 
to have intercourse with the wife when she is breast-feeding because the wife might get pregnant and this can make the child suffer from malnutrition. The child can suffer because it cannot eat all types of food and cannot breast-feed when the mother is pregnant".

Wives said that they discussed modern methods much like their husbands did. However, surprisingly, a number of women indicated that their husbands disagreed with them about the use of modern methods for child spacing. One of the wives said, "my husband only advised me to go to the family planning clinic to learn the different methods and I was taught to choose the best method which is good for me and these methods are the diaphragm loop, pills, injections, and tubes. I chose the pills and my husband agreed with that".

About $40 \%$ of the husbands said that they used abstinence. Nearly the same percentage of wives, about $36 \%$, said they used abstinence. Thus there is some agreement among wives and husbands about the preeminent method used for child spacing.

\section{Discussion}

Far fewer women than men believe that they discussed either the desirable birth interval or the method for spacing. However, a larger proportion of women than men said that they received advice with regard to the desired birth interval. This raises the possibility that there is a communication gap between men and women. Possibly, what men perceive as discussion may come across as advice to women. Regardless of the nature of the perception of discussion, women who received advice about methods for birth spacing were more likely to desire longer birth intervals than the rest. The spacing methods women used did not significantly correlate with the desired length of the birth interval. Among husbands, those who used traditional methods were likely to prefer shorter birth intervals than the rest.

There was strong agreement with respect to the desired birth interval length between husbands and wives. Both husbands and wives desired an average birth interval of about 25 months. However, they offered dissimilar sets of reasons for the desired birth interval. In general, husbands concerned about wives' health preferred longer birth intervals than the rest. Discussion about desired birth intervals were more motivated by heath concerns about children than wives. Very few mentioned economic reasons such as opportunity costs and household expenditures.

In general, more husbands received advice about birth spacing methods than wives. This is perhaps due to the belief that husbands play a more powerful role than wives in reproductive decision making. Discussion about spacing methods involved modern methods. Traditional methods are well known and available. Advice with respect to spacing methods given to husbands may have motivated some discussion of modern methods use among the couples. However, results from multivariate analysis did not find that advice on birth spacing methods was a significant source of influence on men's desired birth intervals.

Broadly stated, birth spacing decisions among Zambian spouses appear to be influenced by noneconomic factors, such as health. In addition, Zambian women appear to be far less able than men to participate in the discussion as well as in obtaining desired birth intervals. The husband's concerns about his wife's health increases the desired birth interval. Birth control programs should consider integrating family health issues with contraceptive services empowering women's reproductive decision making capabilities.

\section{Disclosures}

The authors report no conflicts of interest in this work.

\section{References}

1. Agampodi BS, Agampodi CT, Chandrasekara P. Family planning prevalence among postpartum mothers attending child welfare clinics-A Sri Lankan experience. Indian J Community Med. 2008;34(3):265-268.

2. Thapa S. The ethnic factor in the timing of family formation in Nepal Asia Pac Popul J. 1989;4(1):3-33.

3. Balaiah D, Naik DD, Ghule M, Tapase P. Determinants of spacing contraceptive use among couples in Mumbai: A Male Perspective J Biosoc Sci. 2005;37(6):689-704.

4. Caldwell J. A direct economic costs and benefits of children. In: Bulatao RA, Lee RD, editors. Determinants of Fertility in Developing Countries. New York, NY: Academic Press; 1983. p. 167-189.

5. Beckman L. A communication, power, and the influence of social networks in couple decisions on fertility. In: Bulatao RA, Lee RD, editors. Determinants of Fertility in Developing Countries. New York, NY: Academic Press; 1983. p. 143-167.

6. Caldwell JC, Reddy PH, Caldwell P. The causes of demographic change in rural South India: A micro approach. Pop Dev Rev. 1982;8(4) 251-267.

7. Kritz M, Gurak D, Fapohunda B. A sociocultural and economic determinants of women's status and fertility. Denver, CO: Paper presented at the Annual meeting of Population Association of America; 1992.

8. Oppong C. Female and Male in West Africa. London, UK: George Allen; 1983.

9. Coale AJ. The demographic transition reconsidered. Liege, Belgium: Proceedings of International Population Conference; 1973 Mar $10-15$.

10. Becker S, Lasee A. A husband-wife communication about family planning and contraceptive use in Kenya. Int Fam Plan Perspect. 1997;23(1):1-15.

11. Dodoo NA. Insights into spousal differences in disagreement. Sociol Focus. 1993;26(3):257-271.

12. Ezeh A. The influence of spouses over each other's contraceptive attitudes in Ghana. Stud Fam Plann. 1993;24(3):163-173.

13. Orji EO, Ojofeitimi EO, Olanrewaju B. The role of men in family planning decision-making in rural and urban Nigeria. Eur J Contracept Reprod Health Care. 2007;12(1):70-75. 
14. Mbweza E, Norr KF, McElmurry B. Couple decision making and use of cultural scripts in Malawi. J Nurs Scholarsh. 2008;40(1):12-19.

15. Storey JD, Kaggwa BE. The influence of changes in fertility related norms on contraceptive use in Egypt, 1995-2005. Popul Rev. 2009;48(1):1-19.

16. Bhattacharya SK, Ram R, Goswami DN, GuptaUD, Bhattacharyya K, Ray S. Information study of unmet need for family planning among women of reproductive age group attending immunization Clinic in a Medical College of Kolkata. Indian J Community Med. 2006;31(2):10-14.
17. Kim MY, Kols A, Mucheke S. Informed choice and decision-making in family planning counseling in Kenya. Int Fam Plan Perspect. 1998;24(1):34-42.

18. Fullerton A. A conceptual framework for ordered logistic regression models. Sociol Methods Res. 2009;38(2):306-347.

\section{Publish your work in this journal}

Open Access Journal of Contraception is an international, peerreviewed, open access, online journal, publishing original research, reports, reviews and commentaries on all areas of contraception. In addition to clinical research, demographics and health-related aspects, the journal welcomes new findings in animal and preclinical studies relating to understanding the biological mechanisms and practical development of new contraceptive agents. The manuscript management system is completely online and includes a very quick and fair peer-review system. Visit http://www.dovepress.com/testimonials.php to read real quotes from published authors. 